\title{
CAPÍTULO 10: AULA OU BRINCADEIRAS? A UTILIZAÇÃO DE JOGOS DIDÁTICOS PARA O ENSINO DE EVOLUÇÃO E CLASSIFICAÇÃO FILOGENÉTICA DE VERTEBRADOS
}

\author{
CAPÍTULO 10: ¿LECCIONES O JUEGOS? EL USO DE JUEGOS \\ EDUCACIONALES PARA ENSEÑAR LA EVOLUCIÓN Y LA CLASIFICACIÓN \\ FILOGENÉTICA DE LOS VERTEBRADOS
}

\section{CHAPTER 10: CLASS OR PLAY? THE USE OF TEACHING GAMES FOR TEACHING EVOLUTION AND PHILOGENETIC CLASSIFICATION OF VERTEBRATES}

\author{
Wallace Figuerêdo Barboza ${ }^{1}$; Dan Vitor Vieira Braga ${ }^{2}$
}

DOI: https://doi.org/10.31692/978-65-88970-05-8.144-158

\begin{abstract}
RESUMO
A Teoria da evolução é a base do ensino de Biologia, incorporando a ideia de que todos os organismos do planeta, incluindo espécies extintas e os seres humanos, compartilham ancestrais comuns em algum nível do passado da Terra. Isto tornou a sistemática filogenética uma ferramenta para a análise de padrões evolutivos dos seres vivos que se conectam ao longo de sua história, bem como, subsidiou a classificação dos seres vivos. Porém, é uma das principais dificuldades levantadas pelos alunos ao estudar Biologia, devido a grande diversidade de organismos estudados e a quantidade de termos técnicos a eles associados. Acredita-se que a implantação de novas práticas educativas pode auxiliar o processo ensino-aprendizagem de Biologia. $\mathrm{O}$ objetivo da pesquisa foi desenvolver e aplicar jogos didáticos como ferramentas inovadoras no ensino do conteúdo de Vertebrados e sua classificação. $\mathrm{O}$ presente estudo foi aplicado em uma turma do $2^{\circ}$ ano do Ensino Médio de uma escola Estadual de Referência em Ensino Médio que ainda não haviam vivenciado esse conteúdo. Com intuito de ministrar uma aula usando metodologias inovadoras através de atividades lúdicas para o ensino do conteúdo de vertebrados, foi aplicado como plataforma de aula três jogos didáticos. Um dia após a aula, foi aplicado um questionário de natureza qualitativa e quantitativa, usando questões de múltipla escolha, questões abertas e de verdadeiro ou falso abordando o conteúdo "Vertebrados". Desta forma, avaliaram-se os conhecimentos dos alunos e como o jogo didático pôde ter influenciado no processo de ensino/aprendizagem. Baseado nos dados obtidos observou-se que, apesar do preconceito inicial externalizado, os alunos obtiveram bons resultados com a aplicação do jogo, levando em conta que ainda não haviam visto o conteúdo, e que o jogo didático surtiu efeito positivo no processo ensino aprendizagem baseado nas colocações feitas pelos discentes que gostaram da metodologia.
\end{abstract}

Palavras-Chave: Ensino de Biologia. Ludicidade. Zoologia. Inovação.

\section{RESUMEN}

La teoría de la evolución es la base de la enseñanza de la biología, incorporando la idea de que todos los organismos del planeta, incluidas las especies extintas y los humanos, comparten ancestros comunes en algún nivel del pasado de la Tierra. Esto hizo de la sistemática filogenética una herramienta para el análisis de los patrones evolutivos de los seres vivos que se conectan a lo largo de su historia, así como subvencionó la clasificación de los seres vivos. Sin embargo, es una de las principales dificultades que plantean los estudiantes a la hora de estudiar Biología, debido a la gran diversidad de organismos estudiados y la cantidad de términos técnicos asociados a ellos. Se cree que la implementación de nuevas prácticas educativas puede ayudar al proceso de enseñanza-aprendizaje de la Biología. El objetivo de la investigación fue desarrollar y aplicar juegos educativos como herramientas innovadoras en la enseñanza de contenidos de Vertebrados y su clasificación. El presente estudio se aplicó a una clase de $2^{\circ}$ año de Bachillerato de una Escuela Estatal de Referencia de Bachillerato que aún no había

${ }^{1}$ Ciências Biológicas, FACHUSC, wallace_barboza1990@outlook.com

${ }^{2}$ Mestrado em Gestão e Políticas Ambientais, UFPE, bragadvv@gmail.com 
experimentado este contenido. Para impartir una clase utilizando metodologías innovadoras a través de actividades lúdicas para la enseñanza de contenidos de vertebrados, se aplicaron tres juegos didácticos como plataforma de clase. Un día después de clase, se aplicó un cuestionario cualitativo y cuantitativo, utilizando preguntas de opción múltiple, preguntas abiertas y verdaderas o falsas que abordan el contenido de "Vertebrados". De esta forma, se evaluó el conocimiento de los estudiantes y cómo el juego didáctico pudo haber influido en el proceso de enseñanza / aprendizaje. A partir de los datos obtenidos, se observó que, a pesar del prejuicio exteriorizado inicial, los estudiantes obtuvieron buenos resultados con la aplicación del juego, teniendo en cuenta que aún no habían visto el contenido, y que el juego didáctico incidía positivamente en el proceso de aprendizaje basado en la enseñanza. en las declaraciones realizadas por los estudiantes a quienes les gustó la metodología.

Palabras clave: Enseñanza de la biología. Alegría. Zoología. Innovación.

\section{ABSTRACT}

Evolutionary theory is the basis for teaching biology, embodying the idea that all organisms on the planet, including extinct species and humans, share common ancestors at some level of Earth's past. This made phylogenetic systematics a tool for the analysis of the evolutionary patterns of living beings that connect throughout its history, as well as, it subsidized the classification of living beings. However, it is one of the main difficulties raised by students when studying Biology, due to the great diversity of organisms studied and the amount of technical terms associated with them. It is believed that the implementation of new educational practices can assist the teaching-learning process of Biology. The objective of this research was to develop and apply educational games as innovative tools in teaching Vertebrate content and its classification. The present study was applied to a class in the 2nd year of high school that had not yet experienced this content. In order to teach a class using innovative methodologies through playful activities for teaching vertebrate content, three didactic games were developed and applied as a class platform. One day after class, a qualitative and quantitative questionnaire was applied, using multiple choice questions, dissertative questions and true or false questions addressing the "Vertebrate" content. In this way, students' knowledge was assessed and how the didactic game could have influenced the teaching / learning process. Based on the data obtained, it was observed that the students obtained good results with the application of the game, taking into account that they had not yet seen the content, and that the didactic game had a positive effect on the teaching-learning process based on the placements made by the students who liked it methodology.

Keywords: Biology teaching. Playfulness. Zoology. Innovation.

\section{INTRODUÇÃO}

Sabe-se que um dos objetivos do Sistema Educacional é proporcionar aos alunos a capacidade de aprender, para que sejam futuros cidadãos e aprendizes mais flexíveis, eficazes e autônomos (POZO, 2003). Visando isso, se acredita que as implantações de novas práticas educativas possam auxiliar no processo ensino-aprendizagem (PEDROSO, 2009).

Para Gomes e Silva (2016), a educação vem mudando, exigindo do docente estratégias e ferramentas que auxiliem no desenvolvimento da aula. Sabe-se que existe certa resistência em deixar o ensino tradicional, mas é preciso considerar que os alunos de hoje são de uma nova geração e por este motivo, é necessário que haja uma mudança na maneira de ensinar.

Segundo Seifert e Terán (2011), o ensino de Zoologia nas escolas sofre diversos problemas, tais como: tempo reduzido do professor para planejar e executar aulas práticas em 
laboratórios ou em espaços não formais; o uso exclusivo do livro texto como ferramenta de ensino; professores que utilizam a exposição oral como único recurso didático; deficiência na formação inicial do professor em relação à realidade do ambiente sóciocultural de ensino.

As atividades lúdicas, como jogos didáticos, são eficazes para a contrução de uma aprendizagem significativa, pois preenchem os espaços deixados no curso mais tradicional, onde os alunos são apenas receptores de conhecimentos (CAMPOS et al. 2003).

Segundo as Orientações Curriculares para o Ensino Médio (BRASIL, 2006), o jogo oferece o estímulo e o ambiente propício que favorece o desenvolvimento espontâneo e criativo dos alunos. Além de permitir que o professor possa ampliar seu conhecimento de inovação na didática.

A partir da problemática apresentada dentro do ensino de Biologia, e que muitos professores estão ainda apegados ao método tradicional, o objetivo desta pesquisa foi desenvolver jogos didáticos focados nas possíveis dificuldades de aprendizagem identificadas no ensino do conteúdo de Zoologia, mais especificadamente acerca da compreensão de taxonomia e evolução dos vertebrados. O desafio enfrentado na presente pesquisa foi desenvolver jogos que terão a função de não somente ajudar na retenção do conteúdo teórico, mas sim, de ensinar, de uma forma dinâmica e inovadora, o conteúdo de vertebrados.

\section{FUNDAMENTAÇÃO TEÓRICA}

A Teoria da Evolução é a base do ensino de Biologia. A ideia de que todos os organismos do planeta, incluindo espécies extintas e os seres humanos, compartilham ancestrais comuns em algum momento do seu passado evolutivo teve um impacto profundo após as publicações dos trabalhos de Charles Darwin com o clássico “Origem das espécies por seleção natural de 1859" e Alfred Wallace (SANTOS; CALOR, 2007).

Segundo Dobzansk (1973), o entendimento das Ciências Biológicas só será completo fluido com a compreensão da evolução, e sem ela, a Biologia se torna um aglomerado de fatos sem representação. A Evolução deve permear por todas as disciplinas que constituem a Biologia (ZAMBERLAN; SILVA, 2009) e quando se trata do tema evolução, tanto professores como alunos, relacionam-se com algumas das maiores dificuldades: 1) assimilação da dimensão temporal das mudanças evolutivas, 2) impossibilidade de descobrir os verdadeiros grupos ancestrais dos organismos, 3 ) ideia equivocada de que evolução significa progresso ou melhoria e 4) Barreiras socioculturais que dificultam a aceitação das relações genealógicas entre o ser humano e os demais animais (SANTOS; CALOR, 2007). 
A sistemática filogenética é uma ferramenta para a análise de padrões evolutivos dos seres vivos que se conectam ao longo de sua história (GUIMARÃES, 2005), e também é um método para identificar "parentesco" entre os diversos grupos de seres vivos. Para isso, são realizadas análises comparativas das características presentes nos seres vivos, buscando a identificação de padrões indicativos de ancestralidade baseado nas sinapormofias, ou autapomorfias por eles compartilhadas (RUPPERT; BERNAD, 2005).

Apesar de um início tempestuoso, atualmente a teoria da evolução é considerada hoje uma verdade científica e alicerça os eixos teóricos da Biologia. Conforme esse entendimento comum, os organismos apresentam laços de parentesco evolutivo que os aproximam uns dos outros. Assim, a biodiversidade global é formada pelos indivíduos que apresentam semelhanças e diferenças que variam no tempo, no espaço, na forma e na função (LOPES et al. 2012).

Para promover um ensino/aprendizado coerente em Biologia é necessário entender a dinâmica da vida orientada pelo processo evolutivo identificando as transformações dos organismos através do reconhecimento de suas diferenças e semelhanças ao longo do tempo e comparando com representantes atuais (LOPES et al. 2008).

Candido et al. (2012) afirmam que a classificação dos reinos dos seres vivos é uma das dificuldades levantadas pelos alunos por causa da grande diversidade de organismos estudados, sendo estes abordados desde os primeiros anos do conteúdo de Ciências. Assim, o entendimento do fio condutor da trama evolutiva e o seu ensino contextualizado tornam o aprendizado de zoologia mais significativo e fluido, se comparado a abordagem tradicional baseada na simples decoreba dos nomes dos grupos e de suas características.

Por se tratar de uma construção conceitual contínua, Tindon e Lewontin (2004) afirmam que a má qualidade de trabalho e as lacunas deixadas na formação de professores são alguns dos fatores que colaboram para o surgimento de deficiências no ensino de Zoologia. Já Amorim (2001) acredita que a quantidade de nomes em latim, ou latinizados, utilizadas pelos professores para simples memorização dos alunos, sejam um dos principais fatores.

Atualmente, a metodologia de ensino utilizando o discurso, lousa e giz para obter a atenção dos alunos está totalmente ultrapassada. Se esta metodologia for aplicada nos dias atuais é bem provável que o professor acabe lhe dando com conversas paralelas, uso não pedagógico de celulares em sala de aula, a falta de concentração e outras comportamentos que não colaboram positivamente com o processo efetivo de aprendizagem (LARA et al. 2017).

O Ensino de Biologia deve proporcionar aos estudantes de Ensino Médio uma boa compreensão do dinamismo e integração desse conteúdo. Embora a abordagem mais tradicional 
nos conteúdos de Biologia vem sendo combatida, ainda persiste em muitas salas de aulas (BENEDETTI et al. 2005).

Jan et. al (2010) afirmam que atividades lúdicas como os jogos didáticos, são ferramentas práticas para resolver os problemas como, a falta de estímulo, a carência de recursos e aulas repetitivas além de estimular os alunos desenvolvendo diferentes níveis da sua formação.

Segundo Carvalho e Braga (2013), o jogo didático vem sendo utilizado para facilitar a aprendizagem dos conteúdos de Zoologia, e tem mostrado bons resultados, além disso, tem sido usado dentro de temas que são pouco aprofundados em sala de aula de modo a promover a curiosidade e instigando pesquisa fora da sala de aula.

\section{METODOLOGIA}

A pesquisa foi desenvolvida na cidade de Salgueiro - PE, que está localizada no Sertão Central Pernambucano (Figura 01), com uma população de 56.629 habitantes, e área territorial de $1.686,814 \mathrm{Km}^{2}$ (IBGE, 2017).

Figura 01: Localização geográfica da área de estudo.

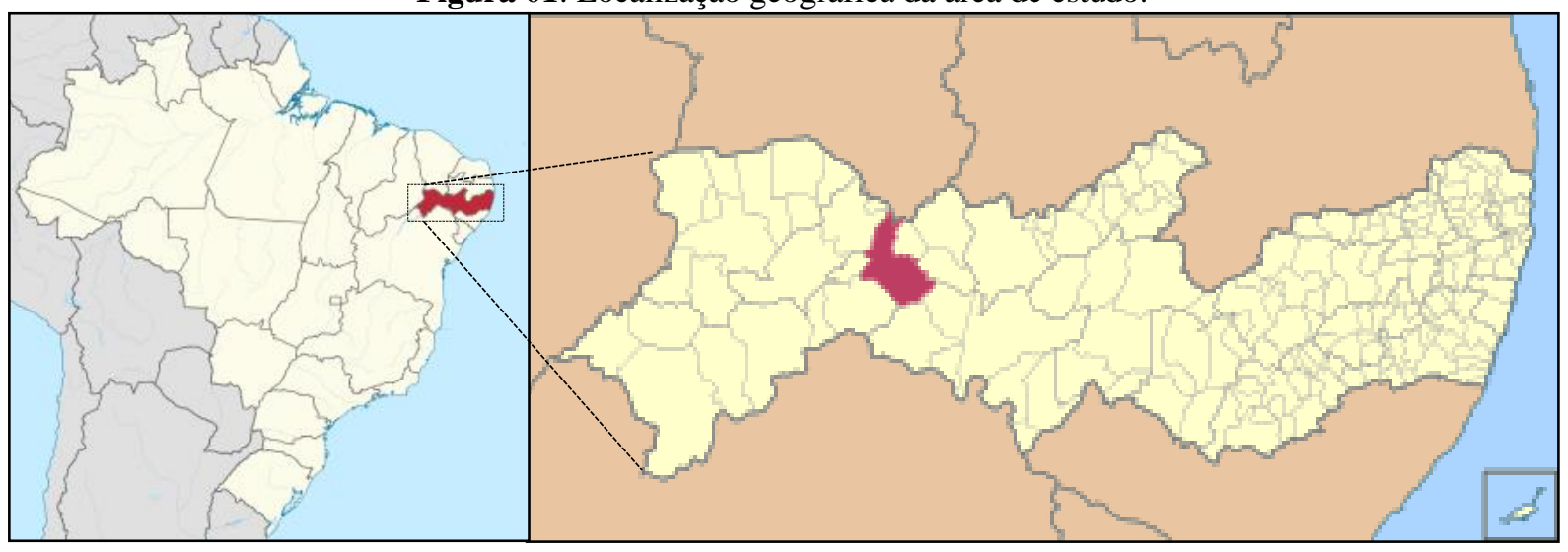

Fonte: Modificado de Wikipédia, 2019.

O estudo foi realizado de agosto a outubro de 2019 e contou com a participação de 32 alunos do $2^{\circ}$ ano de uma escola de Referência em Ensino Médio localizada na região central de Salgueiro, PE. A turma foi escolhida por que ainda não haviam visto o conteúdo de Zoologia relacionado aos Vertebrados.

Inicialmente, com intuito de ministrar aulas usando metodologias inovadoras para o ensino do conteúdo de vertebrados, foi desenvolvido pelos próprios autores e aplicado um jogo didático abordando sua evolução e classificados filogenética. A execuȩão dos jogos foi planejada para ter a duração de duas aulas de 40 minutos cada, uma vez que, esse foi o tempo 
que geralmente é atribuído pelos professores para o ensino deste conteúdo.

Para a execução deste jogo, a turma foi dividida em duas equipes, que competiram entre si. O jogo dos vertebrados consiste em três etapas: a primeira etapa (diagnóstica) consiste de perguntas e respostas relacionadas ao tema de evolução dos grupos de animais vertebrados (Figura 02).

Foram escolhidos três representantes de cada equipe para que pudessem discutir a resposta dentro de um tempo de 30 segundos. Se a equipe erra, ou não responde dentro do tempo estipulado, a mesma pergunta é passada para equipe adversária.

Figura 02: Exemplo do Jogo de perguntas e respostas sobre Evolução de Vertebrados

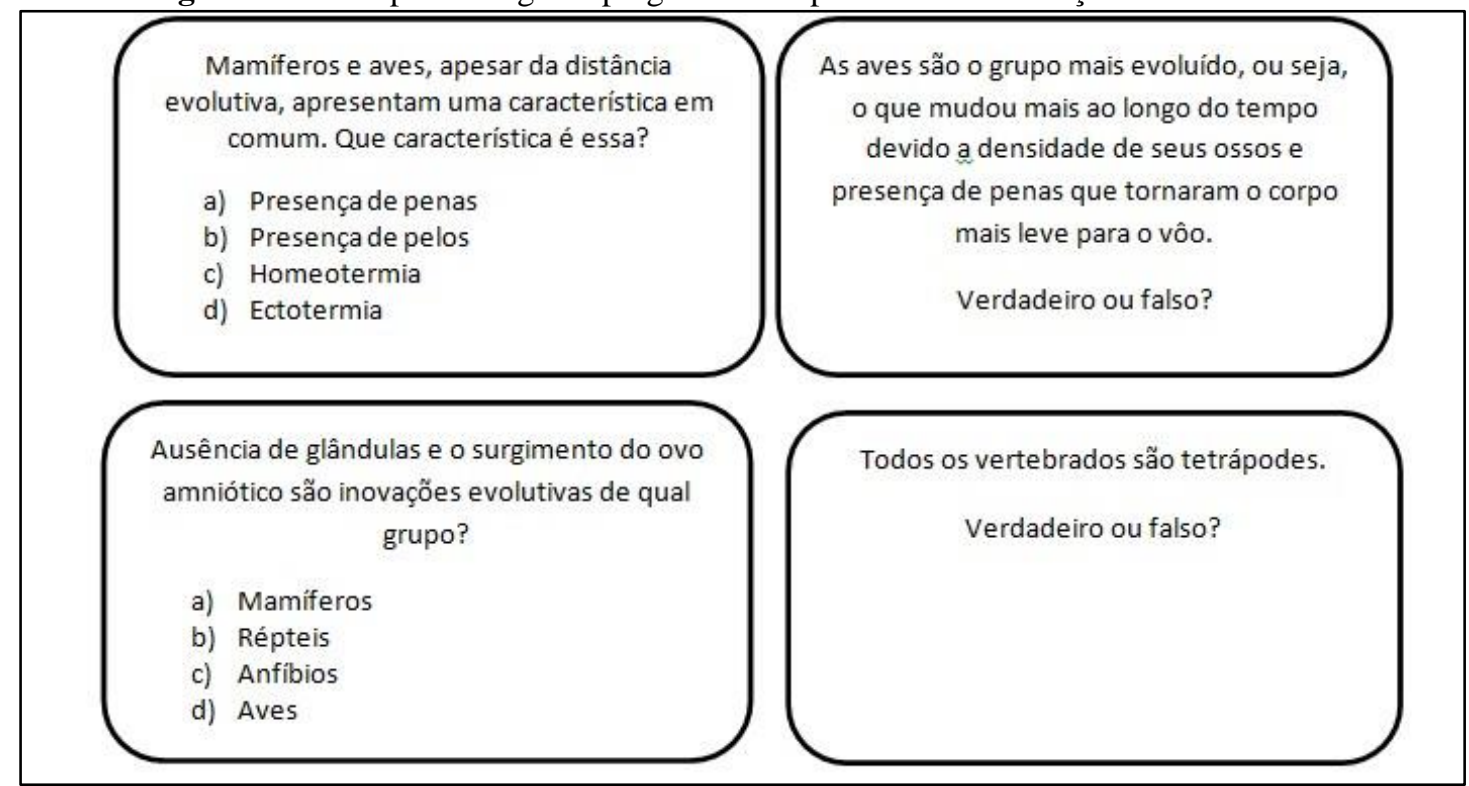

Fonte: Própria (2019)

A segunda etapa foi um jogo de adivinhação, onde se trabalhou as características fisiológicas, morfológicas e comportamentais dos grupos de vertebrados. O aplicador fornece as dicas em três níveis de detalhamento. Inicialmente, as dicas são bastante abrangentes, tornando-se difícil a identificação da resposta, até chegar na terceira dica que é totalmente específica e mais fácil de identificar o grupo ou espécie correspondente (Figura 03).

Figura 03: Exemplo Jogo de advinhação das características dos grupos de vertebrados

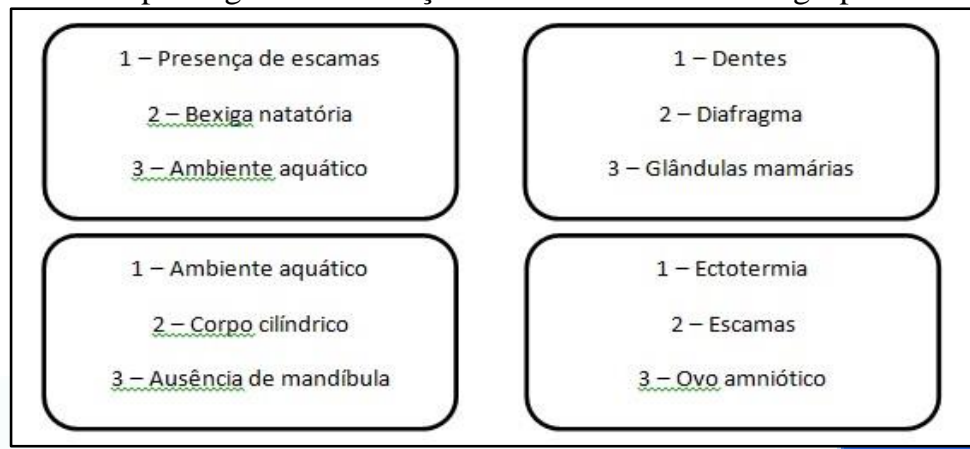

Fonte: Própria (2019) 
Na terceira e última etapa da aula lúdica, foi trabalhado o preenchimento de um cladograma, elemento gráfico utilizado pela fiologenética para a representação dos grupos de seres vivos, suas principais características e relações evolutivas (Figura 04). Foi desenhado no quadro dois cladogramas, um para cada equipe. Neste caso, o cladograma abordou a ordem evolutiva dos grupos representantes dos vertebrados mais primitivos até os mais derivados. Quando já estava representado o grupo zoológico no cladograma, faltavam as suas características e quando se tinha as características, faltava o grupo representante. O desafio consistiu nas equipes preencherem de forma correta o cladograma e dentro de um tempo estipulado de dez minutos.

Figura 04: Modelo do Cladograma usado na terceira etapa do Jogo

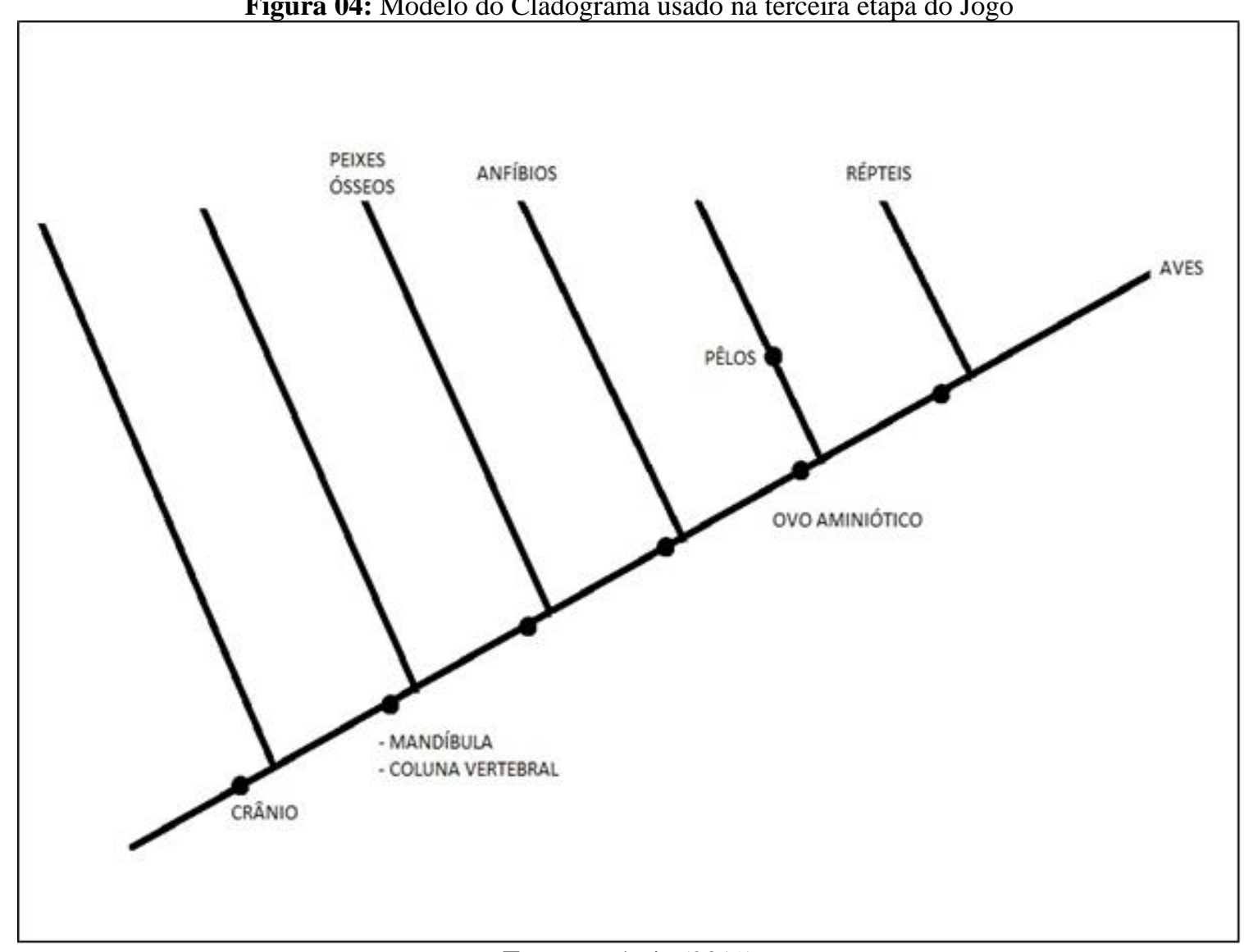

Fonte: Própria (2019)

Para avaliar os conhecimentos dos alunos e como os jogos didáticos podem ter influenciado no processo de ensino/aprendizagem do conteúdo escolhido, foi aplicado um questionário de natureza qualitativa e quantitativa, composto por 10 questões (múltipla escolha, questões abertas e de verdadeiro/falso), abordando o conteúdo de Vertebrados. Este questionário foi respondido individualmente por todos os participantes. As respostas obtidas foram tabuladas e apresentadas a seguir. 


\section{RESULTADOS E DISCUSSÃO}

\section{Nível de Segurança em relação a efetividade do jogo didático como ferramenta exclusiva}

\section{de ensino}

Foi solicitado aos alunos que respondessem se possuíam alguma dúvida sobre o conteúdo dos vertebrados após os jogos. Observou-se que 59\% marcaram a opção talvez, alegando que não viram o conteúdo em sua profundidade, enquanto os $16 \%$ alegaram ter dificuldades com o tema evolução (Figura 05).

Figura 05: Frequência relativa acerca do nível de segurança dos alunos acerca da aprendizagem do conteúdo Vertebrados, após a aplicação dos jogos didáticos.

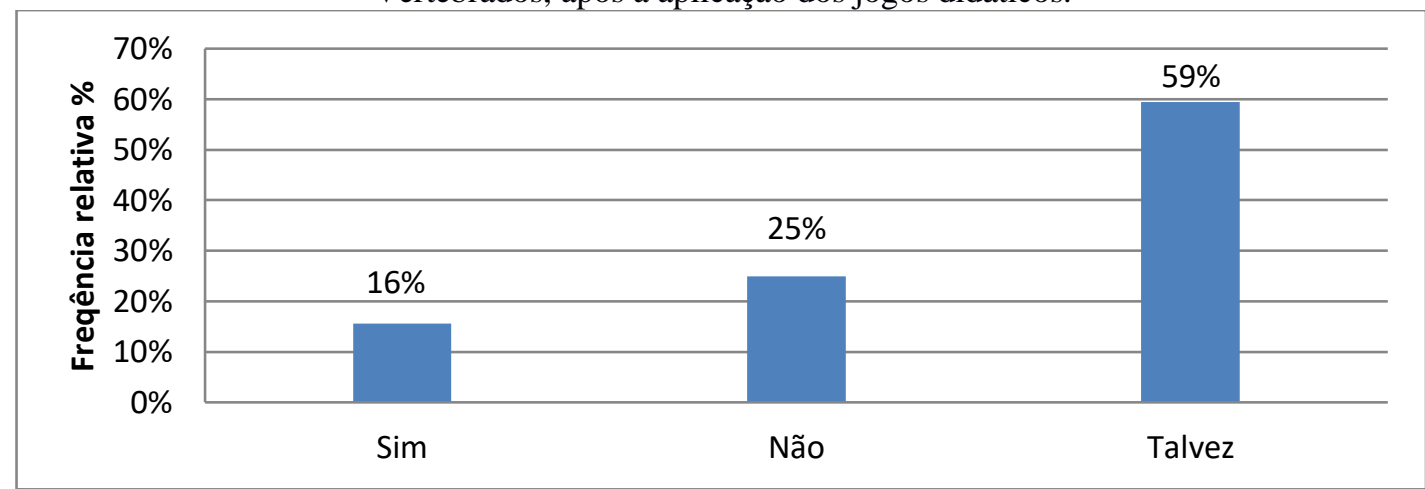

Fonte: Própria (2019)

A insegurança quanto à aprendizagem proporcionada unicamente pelo ensino através da ludicidade corrobora com as observações de Rodrigues (2012), onde 33\% dos professores entrevistados alegaram que seus alunos possuem um grau de preconceito acerca do uso de jogos didáticos como instrumento de ensino. Inclusive, para 34\% dos alunos entrevistados, rejeitaram totalmente o uso de jogos durante as aulas, uma vez que estão acostumados com métodos tradicionais de ensino, onde, na sua percepção, só há ensino se for através de aulas expositivas.

\section{$\underline{\text { Aspectos Acerca da Evolucão dos Vertebrados }}$}

Para se resgatar a história evolutiva dos grupos é necessário entender que as espécies sofrem mutações gerando novas características (apomorfias) e essa característica, quando passa a ser compartilhada por outras espécies que se seguem, indicam, na maioria dos casos, um grau de parentesco evolutivo (OLIVEIRA et al. 2011).

Baseado neste pressuposto, foi elaborado um eixo norteador do direcionado a trabalhar o tema evolução dos vertebrados. Após a atividade lúdica, praticamente todos os alunos participantes $(94 \%)$ acertaram a sequência evolutiva dos Vertebrados, 
afirmando que a ordem evolutiva do mais primitivo ao mais derivado seria do grupo dos agnátos, peixes cartilagenosos, peixes ósseos, anfíbios, mamíferos, répteis e por fim as aves. Isto evidencia que, mesmo inseguros com o ensino através de jogos didáticos, eles compreenderam e assimilaram a ordem evolutiva dos grupos de vertebrados e conseguiram modificar o seu entendimento em relação ao do público em geral que considera erradamente os mamíferos como grupo de vertebrados mais evoluído por conta da visão social antropocêntrica.

Quanto os passos evolutivos específicos ligados a ancestralidade dos Cetáceos (grupo de mamíferos aquáticos), observou-se que houve uma certa dúvida por parte dos alunos quanto a transição desse grupo para o ambiente aquático. Apenas $31 \%$ dos alunos acertaram totalmente a sequência dos passos evolutivos dados pelos representantes deste grupo e $63 \%$ deles acertaram parcialmente, uma vez que disseram que os Cetáceos atuais descendem de ancestrais aquáticos, porém não incluíram o passo evolutivo intermediário dado pelo grupo no ambiente terrestre (Figura 06).

Figura 06: Frequência relativa das respostas relacionadas à evolução dos Cetáceos.

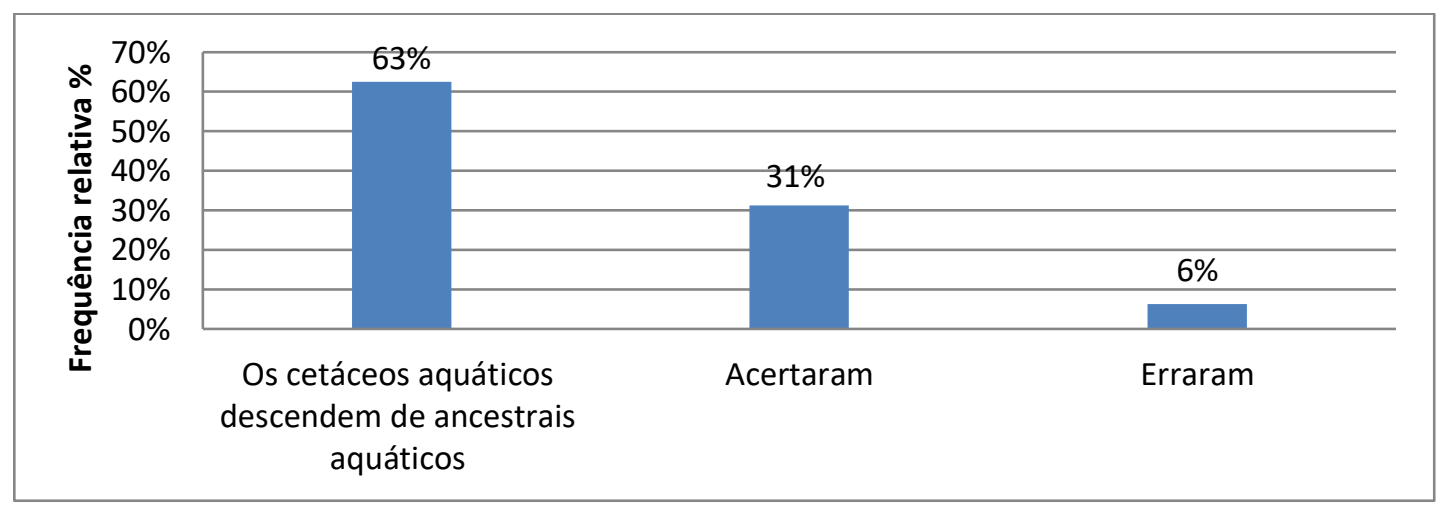

Fonte: Própria (2019)

Braga et al. (2019) afirmam que os fósseis são evidências de espécies que viveram no passado, e que as espécies atuais descenderam de seres ancestrais que foram mudando ao passar do tempo, sendo estas mudanças preservadas nos fósseis. Com a identificação das tendências evolutivas presentes nos registros fósseis, sabe-se hoje que os ancestrais dos Cetáceos eram mamíferos terrestres, provavelmente Artiodáctilos (animais com cascos nas patas e número par de dedos como hipopótamos).

Como a vida iniciou sua evolução na água, a evolução dos cetáceos, contradiz a aplicação da lógica direta e por isso, muitos alunos acertaram parcialmente. Para eles, não teria sentido lógico um grupo de animais retornar ao ambiente aquático, logo após ter passado para o ambiente terrestre. Se os ancestrais mais remotos dos cetáceos são aquáticos, o lógico seria que a evolução os mantivesse no ambiente aquático sem ter o passo evolutivo terrestre intermediário. Porém, nem sempre a evolução teve seu desenvolvimento pautado na aplicação 
antropológica da lógica, e desta forma segue sua própria lógica, cabendo ao professor ajudar os alunos neste entendimento.

\section{Identificacão das características dos grupos}

Sobre as características gerais que definem os vertebrados, 91\% dos entrevistados marcaram a opção correta que afirma que Coluna vertebral; Crânio; Endoesqueleto; Músculos bem desenvolvidos, mostrando um bom aprendizado quanto às definições gerais do grupo.

No questionário, foi solicitado aos alunos para que preenchessem as características dos principais grupos de vertebrados e foi observado mais da metade dos alunos conseguiram caracterizar corretamente todos os grupos. Porém, muitos tiveram dificuldade em alguns grupos, principalmente o grupo dos Agnatos (vertebrados sem mandíbula).

Isto se deve ao fato do grupo ser pouco conhecido pela sociedade em geral e não fazer parte do cotidiano dos alunos. Porém, os alunos também não souberam citar as características dos Anfíbios obtendo a mesma porcentagem de erros observada na descrição do grupo dos Agnatos (Figura 07). Isto leva a crer, assim como afirmado por Lopez et al. (2007), que a prática no ensino de Biologia está distante da realidade do aluno e isso resulta em um ensino pouco significativo na formação do indivíduo como cidadão crítico de sua realidade local.

Observou-se também que houve uma confusão entre as características autopomórficas (exclusivas) e que boa parte dos alunos mencionaram sinapormofias (semelhantes). Como exemplo, no grupo dos Anfíbios, boa parte dos entrevistados responderam como principais características serem tetrápodes ou viver na água e terra. Embora essas características estejam corretas, elas não observadas exclusivamente nesse grupo.

Figura 07: Frequência relativa dos erros observados durante a caracterização dos principais grupos de vertebrados.

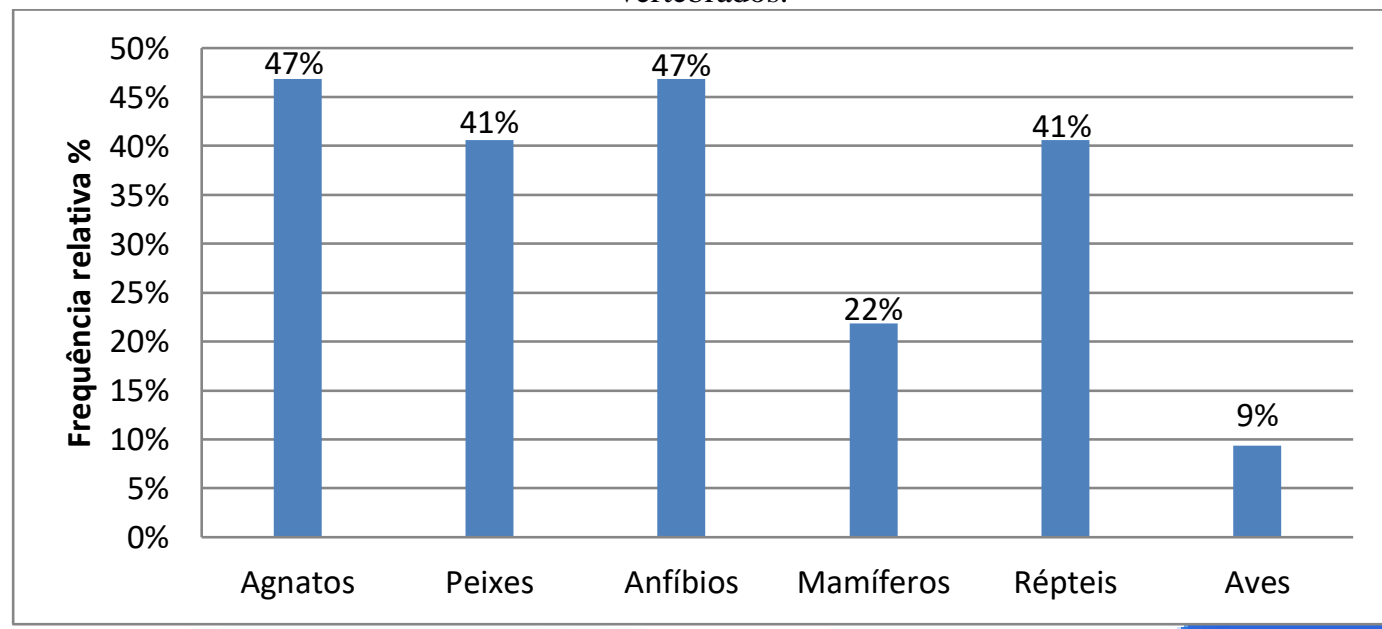

Classificação

Fonte: Própria (2019) 
Segundo Lopez et al. (2007), para se ter um ensino adequado nas áreas de sistemática filogenética e taxonomia zoológica, é necessária uma compreensão sobre os processos evolutivos e as mudanças nos organismos vivos. Para Amorim (2001), a sistemática filogenética tem como objeto central a diversidade biológica, procurando encontrar uma possível ordem e entender as possíveis causas para formação dessa diversidade baseado na ancestralidade comum.

Desta forma, para identificar se os alunos conseguiram assimilar este eixo norteador presente nos jogos didáticos utilizados foi incluída no questionário avaliativo uma questão na qual eles teriam que diferenciar uma imagem de cladograma, de imagens de árvores filogenética. Ao analisar as respostas dos alunos, observou-se que 75\% deles responderam corretamente demonstrando eficácia no jogo em abordar este eixo temático.

Praticamente todos os alunos entrevistados (91\%) demonstraram aprendizado na leitura e interpretação de cladogramas conseguindo, através da visualização da imagem de um cladograma, identificar a ordem evolutiva dos principais representantes dos grupos de vertebrados. Além de identificar o grupo mais primitivo em comparação ao mais derivado (“evoluído").

A capacidade do jogo didático em explicitar a contribuição prática do conteúdo Vertebrados na vida dos alunos foi reconhecida por $94 \%$ dos entrevistados. Dentre as respostas obtidas, nove foram selecionadas por externalizar a relevância do conteúdo trabalhado na vida dos alunos (Tabela 01).

Tabela 01: Respostas dos alunos sobre como o conteúdo "Vertebrados" pode contribuir na sua vida.

\begin{tabular}{cc}
\hline Aluno & Respostas \\
\hline 1 & "Para sabermos como a evolução aconteceu" \\
2 & "Vai me ajudar na faculdade de medicina" \\
3 & "Vou ter conhecimento sobre evolução" \\
4 & "É importante sabermos sobre a evolução dos animais, pois ao \\
& aprendermos sobre isso pode nos ajudar na compreensão de onde tudo \\
5 & começou e de onde viemos também" \\
6 & "É necessário saber o surgimento e a evolução dos animais para \\
7 & "Pontendermos como os seus sistema funcionam atualmente" \\
8 & "Pue ajuda a perceber de onde viemos e as evoluções que passamos" \\
& "Por que vamos descobrir mais as nossas origens"
\end{tabular}


"Vestibular ou se escolhermos algo relacionado a Biologia"

\section{Fonte: Própria (2019)}

Nota-se que os alunos enfatizaram muito a importância da evolução para o entendimento de onde o ser humano surgiu como espécie, como tudo começou e quais as origens do ponto de vista biológico, pois perceberam que a espécie humana faz parte dos vertebrados. Isto leva a entender que, de alguma forma, os alunos encontraram na ciência evolutiva uma maneira de obter possíveis repostas sobre a origem da espécie humana.

Metade dos entrevistados conseguiu compreender que os Mamíferos não são o grupo mais evoluído dos vertebrados, afirmando que as Aves são o grupo mais evoluído. Porém, a aplicação dos instrumentos lúdicos não foi suficiente para $31 \%$ dos alunos apontaram que mantiveram a interpretação antropocêntrica inicial de que os Mamíferos seriam o grupo de vertebrados mais evoluídos. Eles embasaram seus pontos de vista, alegando que os Mamíferos "são seres inteligentes, com capacidade de raciocínio rápido e mais capacidade de locomoção", preconceitos a muito tempo refutados por estudos comportamentais e descontruídos na maioria dos livros textos de biologia, porém ainda socialmente persistentes.

Isto evidencia dois aspectos socioculturais na construção da aprendizagem deste conteúdo: o primeiro relacionado à visão social e teológica antropocêntrica que colocaria o Mamífero como grupo mais evoluído por nele estar incluso a espécie humana. A segunda relaciona-se ao fato de muitos terem dificuldade de entender como a evolução acontece e como as características foram surgindo.

Nas justificativas apresentadas pelos alunos, observa-se uma forte evidência de possíveis conflitos entre o conceito de evolução como melhoria x evolução como mudança, corroborando com Carneiro (2004) que afirma que a falta de coerência no ensino de Zoologia e nos conceitos desenvolvidos em sala de aula, as falhas conceituais que também existem nos livros didáticos e nos cursos de formação dos professores, são problemas que interferem no processo de ensino/aprendizagem. Uma vez que muitos professores ensinam a evolução como melhoria, por terem esta visão deturpada deste conceito tão crucial para o entendimento deste conteúdo.

\section{CONSIDERAÇÕES FINAIS}

Baseado nos dados obtidos, observou-se que os alunos, apesar se declararem inseguros com a eficácia do ensino através de jogos didáticos, obtiveram bons resultados de aprendizagem, levando em conta que não haviam vivenciado anteriormente o conteúdo. Isto 
demonstra que utilização dos jogos didáticos como a plataforma de aula surtiu efeito positivo no processo aprendizagem do conteúdo escolhido. O desafio lançado no planejamento inicial da pesquisa foi alcançado e os jogos conseguiram ter a função de não somente ajudar na retenção do conteúdo teórico, mas sim, de ensinar, de uma forma dinâmica e inovadora, o conteúdo de vertebrados.

A maioria dos alunos participantes obteve sucesso no entendimento sobre Evolução Biológica, na interpretação de cladogramas e na identificação das características dos principais grupos de vertebrados e, incluindo neste contexto a espécie humana. Por fim, as estratégicas de ensino inovadoras aqui expostas permitiram quebrar os preconceitos inicialmente externalizados pelos alunos e professores em relação à utilização dos jogos didáticos como a plataforma de ensino e não apenas como estratégia de retenção ou avaliação de aprendizagem.

\section{REFERÊNCIAS}

Amorim, D. S., MONTAGNINI, D. L., CORREA, R. J., NOLL, M. S. M. C.; NOLL, F. B. (2001). Diversidade biológica e evolução: uma nova concepção para o ensino de zoologia e botânica no $2^{\circ}$ grau. In: CARVALHO, C.P. de. A construçãa do conhecimento do professor: uma experiência de parceria entre professores do ensino fundamental e médio da rede pública e a universidade. Ribeirão Preto: Holos.

BENEDETTI, J.; DINIZ, R.; NISHIDA, S. O jogo de representação (RPG) como ferramenta de ensino. Instituto de Biociências da Universidade Estadual Paulista "Júlio de Mesquita Filho"(org.), Anais do I Encontro Nacional de Ensino de Biologia e III Encontro Regional de Ensino de Biologia da Regional RJ/ES. Rio de Janeiro: UFRJ, 2005.

BRASIL. Ministério da Educação. Secretaria de Educação Básica. Orientações Curriculares para o Ensino Médio: Ciências da natureza, matemática e suas tecnologias. Brasília: MEC/SEB, 2006. 135 p.

BRAGA, D. V. V.; BARBOZA, W. F; RODRIGUES, F. W. A; Evolução Biológica: O clássico dualismo nas concepções dos alunos entre criacionismo e evolucionismo. In:

DALAZOANA, K. (org). Fundamentos e Aplicações da Biologia. Ed. Ponta Grossa: Atena, 2019. P. 155-151. Disponível em:

https://www.atenaeditora.com.br/arquivos/ebooks/fundamentos-e-aplicacoes-da-biologia.

Acesso em: 14 out. 2019.

CANDIDO, C.; PRAMPERO, A.C.; SOARES, C.A.P.; GOMES, T.H.P. Recursos no ensino e aprendizagem: elaboração de um material didático sobre o tema Artrópodes destinado a alunos do Ensino Fundamental e Médio. Cadernos da Pedagogia, v.5, n.10, p.83-91, jan/jun, 2012.

CAMPOS, L. M. L.; BORTOLOTTO, T. M.; FELICIO, A. K. C. (2003). A produção de jogos didáticos para o ensino de Ciências e Biologia: uma proposta para favorecer a aprendizagem. Caderno dos Núcleos de Ensino. São Paulo. p. 47-60. 
CARNEIRO, A. P. N. A evolução biológica aos olhos de professores nãolicenciados. 2004. 119 f. Dissertação (Mestrado em Educação) - Centro de Ciências da Educação, Universidade Federal de Santa Catarina, Florianópolis, 2004. Disponível em: https://repositorio.ufsc.br/bitstream/handle/123456789/87246/210787.pdf?sequence=1. Acesso em: 10 out. 2019.

CARVALHO, E. F. F.; BRAGA, P. E. T. (2013). O jogo de tabuleiro como uma estratégia auxiliadora para o ensino de Zoologia, com ênfase para as serpentes. Ensino, Saúde e Ambiente. v. 6. n. 3, p. 202-217.

DOBZHANSKY, THEODOSIUS. Nothing in biology makes sense except in the light of evolution. The American Biology Teacher, 2013, 75.v. 2; p. 87-92.

GUIMARÃES, M. A. Cladogramas e Evolução no Ensino de Biologia. 2005. Dissertação (Mestrado em Educação para a Ciência) - Faculdade de Ciências, Universidade Estadual Paulista Júlio de Mesquita Filho, Bauru, 2005.

GOMES, C. R. de P.; SILVA, F. A. R. O "Mistério no Zoo": um jogo para o ensino de zoologia de vertebrados no ensino fundamental II. Revista da SBEnBIO, v. 9, p. 202-211, 2016. Disponível em: http://www.sbenbio.org.br/wordpress/wp-content/uploads/renbio9/pdfs/1598.pdf . Acesso em: 30 Abr. 2019.

IBGE. IBGEcidades.ibge.gv.br . Atualizado em 2017. Disponível em: http://www.cidades.ibge.gov.br. Acesso em 14 de abril. 2019.

JANN, PRISCILA NOWASKI; DE FÁTIMA LEITE, MARIA. Jogo do DNA: um instrumento pedagógico para o ensino de ciências e biologia. Ciências \& Cognição, v. 15, n. 1, p. pp. 282-293, 2010.

LARA, P.; BOZZA, E. C.; JAROCHYNSHI, N. F.; KAICK, T. V.; PROCOPIAK, L. K. Desenvolvimento e aplicação de um jogo sobre interações ecológicas no ensino de Biologia. Investigações em Ensino de Ciências. v. 12, n. 8, p. 261-275. 2017

LOPES, W. R.; VASCONCELOS, S D.; Representação e distorções conceituais do conteúdo "filogenia" em livros didáticos de biologia do ensino médio. Ensaio Pesquisa em Educação em Ciências, vol. 14, núm. 2012, p. 149-165. Universidade Federal de Minas Gerais. Minas Gerais, Brasil

LOPES, W. R.; DE MELLO FERREIRO, M. J.; STEVAUX, M. N. Proposta Pedagógicas para o Ensino Médio: filogenia de animais. Revista Polyphonía, v. 18, n. 2, p. 263-263, 2007.

OLIVEIRA, D. D., SOUZA, L. D., LUZ, C. F. S., SOUZA, A. L. S., BITENCOURT, I.M. SANTOS, M. D. O. Ensino de Zoologia numa perspectiva evolutiva: análise de uma ação educativa desenvolvida com uma turma do Ensino Fundamental. Encontro Nacional de Pesquisa em Educação em Ciências, v. 8, 2011.

PEDROSO, C.V. (2009). Jogos didáticos no ensino de biologia: uma proposta metodológica baseada em módulo didático. In: IX Congresso Nacional de Educação-EDUCERE. III Encontro Sul Brasileiro de Psicopedagogia. Anais... PUCPR, Curitiba. 
RODRIGUES, J.N. Ludicidade: o jogo como uma ferramenta no processo de ensino aprendizagem no $5^{\circ}$ ano do ensino fundamental. 2012. 52 f., il. Monografia (Licenciatura em Educação Física)—Universidade de Brasília, Macapá-AP, 2012.

RUPPERT, E. E., Fox, R. S.. BARNES, R. D. (2005). Zoologia dos invertebrados: uma abordagem funcional-evolutiva. $7^{\mathrm{a}}$ ed., Roca, São Paulo, 1145p.

SANTOS, C. M. D.; CALOR, A. R. Ensino de biologia evolutiva utilizando a estrutura conceitual da sistemática filogenética - I. Ciência e Ensino, v. 2, n. 1, 2007.

SEIFFERT-SANTOS, S.C.; FACHÍN-TÉRAN, A. Possibilidade do uso de analogia e metáfora no processo de ensino-aprendizagem no Ensino de Zoologia no $7^{\circ}$ ano do Ensino Fundamental. In: Congresso Norte Nordeste de Ensino de Ciências e Matemática, 8. Anais... Boa Vista: UERR, 2009. Boa Vista

TIDON, R.; LEWONTIN, R.C. Teaching evolutionary biology. Genetics and Molecular Biology, 27, p. 1-8, 2004.

ZAMBERLAN, E.; Da SILVA, M. R. O evolucionismo como princípio organizador da biologia. Temas \& Matizes, v. 8, n. 15, p. 27-41, 2009. 